\title{
Editorial: Circle Time
}

'Pupils and teachers will sit together in a circle, and the teacher begins by showing the pupils a video clip, image or newspaper article with a philosophical dimension, to stimulate their interest. This is generally followed by a short period of silent thinking time, before the class splits into pairs or small groups to generate questions that interest them. A question with philosophical potential is chosen by the group to get the whole class talking. These dialogue sessions are supported by activities to develop children's skills in reasoning and their understanding of concepts.'

So runs a large-scale trial of philosophy for nine and ten year olds, conducted recently in 48 schools in Britain. Teachers on the scheme were given two days of 'professional training', and favoured topics included truth, knowledge and fairness.

Readers of John Dewey will no doubt be heartened to hear of the activity of pairs of pupils, the use of group work and the generation by pupils of questions that interest them, to say nothing of the development of their skills in reasoning, while some may be impressed to see the influence of John Rawls (fairness) reaching so far down the educational ladder.

It is noteworthy, though, that the press release announcing the outcome of the trials is entitled 'PHILOSOPHY SESSIONS FOR DISADVANTAGED TEN YEAR OLDS CAN BOOST THEIR READING WRITING AND MATHS RESULTS' (punctuation and capitals theirs). That is obviously a good thing, though it is not entirely out of place to wonder if those results might have improved even more had the children been properly taught reading, writing and maths in the first place (and rather before they were nine or ten).

Still, the utilitarian rationale aside, are we seeing here the conversations of mankind flourishing among even the youngest of pupils? But before becoming too sanguine at this point, it may not be too unkind to summon the shades of the ancient Greeks, Plato and Aristotle notably, who, unlike Dewey, seemed to think that fruitful reasoning on philosophical, ethical and political matters, required a level of knowledge and experience uncommon in the average ten year old.

Further the very notion of generic reasoning skills, on which this and much other well-intentioned work in education rests today, is open to question. After all, one does not need to delve very deep 


\section{Editorial}

into recent philosophical history to notice that some very good logicians have been quite poor when they turned their attention to moral and social matters. Sensitivity in literary criticism is, unfortunately, no guarantee of clarity in other areas, while eminence (genuine eminence) in science can go hand in hand with a blind spot concerning religious matters (and possibly vice versa too).

At the very least, from a professional point of view, it is comforting to reflect that the very notion of philosophy emerging from the reactions of nine and ten year olds to video clips and newspaper articles itself raises tricky philosophical questions, on examining which adult philosophers might be surprised to find they have a range of conflicting views. 